\title{
The process of teacher education for inclusion: the Maltese experience
}

\author{
Paul A. Bartolo \\ University of Malta, Malta
}

Key words: Social inclusion, inclusive education, teacher education, pedagogy, inclusive development.

This paper discusses major challenges for the development of teacher education for inclusion through an analysis of relevant recent experience in Malta. Inclusion in society and in education has been explicitly on the Maltese national agenda for the past two decades. The Faculty of Education of the University of Malta has been one of the main actors of the inclusion initiative and has also taken a European initiative through the recent co-ordination of a seven-country, 3-year European Union Comenius project on preparing teachers for responding to student diversity. This paper is based mostly on the reflective experience of the author at the Faculty of Education over the past several years. A brief picture of the Maltese education system is followed by a description of the challenges that have been encountered in the promotion of inclusion. These include the development of a rights-based approach to the education of persons with disability and the widening of its application to all minority or disadvantaged groups, and the impact of political and social contexts on the development of inclusive schools. These developments are then related to intertwined initiatives for teacher education for diversity that were further influenced by the leadership of deans and heads of the department in the faculty of education. Finally, four current issues are highlighted, namely: the strategic balance between the education of specialist educators and that of all teachers for diversity, and between specific and infusion models for such education, and, finally, the pedagogic balance between the academic and experiential learning about inclusion, and between the theory and practice of inclusive teaching.

\section{Introduction}

In Malta, the preparation of teachers for inclusion is rooted in a cultural-historical context linked to the development of a more inclusive society with implications for the education system as a whole. This introduction gives a brief account of recent developments in the education system of Malta, a republic and a member of the European Union (EU) since 2004. The population of Malta is 400000 people living on two small islands in the centre of the Mediterranean.
The gradual development of inclusive education can be traced to the introduction of compulsory primary education for all children from age 5 through 14 years in 1946, which was fully implemented by the early 1950s. Despite Malta's long cultural history extending to at least $5000 \mathrm{BC}$ and the existence of the University of Malta for over 400 years, it was the introduction of compulsory education that led to the first attempts to ensure that no children were prevented from access to public education (Bartolo, 2001).

The idea of education as a need and right for all was further strengthened in the 1970 s by the extension of secondary education to all students, the raising of compulsory education from 14 years to 16 years and the setting up of statesupported kindergarten centres for 4-year olds. By the 1990 s, $95 \%$ of 3-4-year olds were attending school regularly (Zammit Mangion, 1992). The first education act was passed in 1974 and revised in 1988. These acts entitled every child, including those with disability, to a public education (Zammit Mangion, 1992). Public special education services were initiated through British influence in 1956 and continued expanding until the 1980s.

The early integration of children with disabilities into mainstream schools also resulted from British influence through the Warnock (1978) Report. Thus, by 1986, although 0.8\% of children were segregated in special schools, there were another $0.2 \%$ (121) of children identified as having special needs who were in special classes in regular schools. Additionally, a British style 'Statementing' process for identifying and assessing children who are experiencing difficulties in the education system has been in place since 2000. Currently, 2080 students (3.4\% of the total population) have a formal Statement of Individual Educational Needs (IEN) and are supported on a one-on-one or shared arrangement by 1545 learning support assistants (LSAs) within regular classrooms, whereas only $236(0.38 \%)$ are in special schools (Bartolo and Borg, 2009). There has been excessive pressure on expanding the mainstream individual support arrangements to address the needs of any child who is not coping with a rigid curricular system: This has raised concerns about its cost-effectiveness as well as on how far it is truly promoting the inclusion of children with IEN (Spiteri, Borg and Callus et al., 2005).

Maltese education is quite homogenous. Two-thirds of the 61000 students from 3 years to 16 years attend state 
schools. Most of the other third are in Catholic Church schools (which also are funded by the state), with about $10 \%$ in independent (private) schools. More recently, a small school for the Muslim community has been set up, which is interestingly run by a Catholic head of school and mostly Catholic teachers. Children in all schools move from kindergarten (ages 3-4) to primary (ages 5-10), to secondary (ages 11-15), and around 60\% to sixth form or postsecondary vocational courses (ages 16-17). The Malta College of Arts, Science, and Technology offers postsecondary vocational courses. In addition, 10000 students, and around 700 international students, attend the University of Malta. There are now small branches of foreign universities offering particular tertiary courses, but only the University of Malta offers teacher education courses.

Malta's educational establishment resembles that for a single town or region in larger countries. There is one central division of education that determines the funding, curriculum and employment of school personnel in all state schools, though these are now divided into 10 semiautonomous clusters. Whereas administrators and educators in larger countries generally use their national policy and legislation to establish educational standards, the Maltese generally refer and defer to standards developed in other countries: initially, to British standards; then, on becoming independent in 1964, to United Nations (UN) standards; and, more recently, to EU agendas.

There is a very competitive academic culture in schools and the community with examinations being a high feature for children, families and schools. Until 1971, a very selective $11+$ national examination system was used to certify educational attainment and serve a streaming system that started from the first years of primary school. It was replaced for a brief period in 1972-1981 by the introduction of comprehensive education in state schools. However, lack of proper planning for the change turned it into a sour experience for Maltese state education and led to the accelerated expansion of church and independent schools, which remained selective (Zammit Marmara, 2001). Consequently, in 1981, a rigid national examination and streaming system was reintroduced, starting from the age of 8 years and leading to an 11+ examination for entrance into grammar schools. This system has since been severely criticised as being the opposite of inclusive education (e.g., King, Bartolo, Borg et al., 2000) and has been seen as leading to substantial dropouts from the education system so that Malta has had the lowest level of students in postsecondary education in the EU. Consequently, a reform of this system has been introduced, which will lead to the elimination of the $11+$ selective examination by 2011 in all schools including church schools.

The reform of the competitive academic culture is being introduced gradually and with a substantial increase in in-service courses for teachers. There are also attempts to change the design of the curriculum, which has hitherto been very rigid, organised by year level syllabi and tied to the content of national examinations. In general, classroom instruction still relies on whole-class teaching methods, particularly in secondary education. As a result, many teachers are still in favour of streaming, particularly in secondary schools.

\section{Two major developments towards inclusive education}

Within the above context, Maltese educators have experienced two intertwined developments towards inclusive education that are generally similar to other more developed Western education systems, particularly as described for Norway, though occurring with a delay of around two decades (Emanuelsson, Haug and Persson, 2005). These are: (1) the deepening of the understanding of the concept of inclusion in relation to disability accompanied by the introduction of more respectful terminology, and (2) widening the inclusion agenda to all marginalised groups. Each of these developments is discussed below.

\section{The deepening understanding of the concept of inclusion}

The first important development was the change from a charitable approach to disability to one based on human rights (see Brown, 2005; Daniels and Garner, 1999). This has been accompanied by the introduction of new terminology for persons with disability that arose from the social model in the UK (e.g., Manchester City Council, 2010). The new terminology has been aimed at reflecting an important change from the concept of charitable respect for children and persons 'who are less fortunate' to a new understanding that each person is entitled to a quality education and life by right, and deserves respect as an equal human being rather than being pitied by others (Bezzina, 2007).

Thus, the first national-level services for persons with disability were set up by the Catholic Church as a charitable institution. However, a socialist government in the 1970s that emphasised support for the weak, parental pressure and UN developments towards respect for persons with disability led to a new slogan by the political centre-right party elected to government in 1987: 'The handicapped will be one hundred per cent citizens'. To achieve this, the new administration immediately appointed a 'National Commission for the Handicapped', later (in 1992) termed 'National Commission for Persons with Disability' (in Maltese 'Kummissjoni Nazzjonali Persuni b'Dizabilita' - KNPD: http:// www.knpd.org). The activities of this commission have had the continuing support of the whole political system. Thus, in a recent election campaign, the two major parties emphasised inclusion with two quite similar slogans: 'So no one will be left out' and 'So no one is left behind'. Meanwhile, the KNPD has acted as a watchdog and promoter of the rights and services for persons with disability, leading to the enactment of the Equal Opportunities (Persons with Disability) Act (2000). One of the KNPD's recent publications was one of guidelines, mainly for non-governmental organisations (NGOs) and the media, to adopt the social model approach to disability: Rights not charity (Bezzina, 2007). This approach has led to increasing self-advocacy and increasing participation of persons with disability in all community activities. The political influence of the KNPD was also evident in the fact that in 2007, Malta was one of 
the first UN member states to sign the new International Convention on the Rights of Persons with Disability and its optional protocol with the intention to start the process to eventually ratify these international instruments (KNPD, 2009). However, Malta registered reservations on the use of abortion and of electoral procedures, and has in fact not yet ratified the Convention.

The KNPD has also spearheaded relevant changes in the designation of persons with disability. Up to two decades ago in Malta, it was common to refer to persons with disability as 'the handicapped'. However, this term is now regarded as denigrating the dignity of persons with disability who are, first of all, persons like everybody else with similar human rights and needs, and has been replaced by the phrase persons with disability. Interestingly, because of the way it was introduced in Malta, the term disability (dizabilita) is preferred as a more respectful term than any Maltese translation of the term impairment. Within education, the main current terms in use are students with disability or students with IEN. Malta had borrowed the term students with special educational needs (SEN) from Warnock (1978) as a progressive one intended to replace the medical focus on the deficits within students with an indication of the need for special provisions that schools had to make to ensure each child's progress (Organisation for Economic Co-operation and Development, 1999) - similar to the Scottish use of the term 'students with additional needs'. However, the term 'special' in SEN has been criticised in Malta particularly by the KNPD because it may be construed as patronising (cf. Williams, Lamb and Norwich et al., 2009; and Barton and Tomlinson, 1981, for another view). This led to the introduction of the new term, IEN, that is now officially used in Maltese education following the proposal of a recent national curriculum focus group on inclusive education:

'This document [Creating inclusive schools] uses the term students with Individual Educational Needs (IEN) instead of the other current terms (students with special educational needs, students with learning difficulties or with impairments or with disability). This will avoid stigmatising such students as special and help us regard them as part of the normal diversity among all students. In this way, it is hoped that we will start viewing all students as lying within a spectrum of common and individual needs that should be met as far as possible within regular education provision. An inclusive education approach should view all students as learners with equal rights but with a diversity of needs. Education provisions should then be designated as either general (for all students) or individual (for one particular student). This term also links directly to the Individual Educational Programme that sets out those provisions that are individualised for that particular student. IENs may include needs for particular provisions due to giftedness.' (Bartolo, Agius Ferrante and Azzopardi et al., 2002, p. 1)
Another still currently relevant distinction of concepts and terminology has been related to two different inclusive educational arrangements, namely, integration (sometimes also referred to as mainstreaming) and inclusion. Integration had become the progressive word in education in the 1970s in Malta, as in the USA and UK, for the new impetus to move children out of special and into mainstream schools. However, the term has, since the 1990s in Malta, been derogatorily defined as the attempt to make students with disability fit into regular schools (Bartolo, 2003; cf. Daniels and Garner, 1999; United Nations Educational and Scientific Organization [UNESCO], 2005). A similar downgrading was made of the equivalent term mainstreaming in the USA, and subsequently in Malta, as it was taken to refer to the mere placement of students with disability into mainstream schools without any corresponding changes in the schools (Stainback and Stainback, 1990).

It is worth noting here that the use of each term is contextualised in time and place. For instance, the current use of the term mainstreaming in relation to disability at UN level seems to be closer to that implied in 'inclusive' approaches, although still being used together with 'integration':
'Disability experts from around the world ... stressed the need to mainstream disability in all development activities in order to achieve equality for persons with disabilities. Panelists highlighted the fact that since persons with disabilities represent such a significant portion of the population, $10 \%$, and are more likely to live in poverty than their peers without disabilities, ensuring that they are integrated into all development activities is essential in order to achieve internationally agreed development goals.' (UN, 2008, my italics)

The terms integration and inclusion were initially used interchangeably, even internationally: 'the integration of children and youth with special educational needs is best achieved within inclusive schools that serve all children within a community' (UNESCO, 1994, para 6, my italics). However, in Malta, the term inclusive education was introduced to the education system to denote a new movement beyond integration. The notion came from the USA: inclusion is about 'how to develop regular school and classroom communities that fit, nurture, and support the educational and social needs of every student in attendance' by making the regular school 'a place where everyone belongs, is accepted, supports, and is supported by his or her peers and other members of the school community' (Stainback and Stainback, 1990, pp. 3-4). Maltese promoters levered the concept with statements from the influential Salamanca Statement that are closely reflected in the National Minimum Curriculum (NMC):

\footnotetext{
'Each school is endowed with a vast repertoire of skills, experiences and needs. This diversity, allied with the individual and social differences evident in the student population, enables and requires a pedagogy based on respect for and the celebration of
} 
difference ... Students learn differently: different students learn differently what is being taught. There are those who learn best through concrete experiences; others who learn best through abstract thinking and concepts. Some students prefer didactic methods; others enjoy learning on their own; still others prefer to work in groups. Teachers should be aware of these differences and their pedagogical implications so that they can engage in a more effective pedagogical approach based on the provision of different learning experiences.' (Ministry of Education [MOED], 1999, principle 2; cf. UNESCO, 1994, para 7)

Despite this clear policy distinction, the challenge for inclusive practice rather than mere integration remains an almost elusive one. The situation is captured well in the description used for a similar situation in Norway:

'Children are still either taken out of class to receive special education alone or in small groups, as in special schools, and/or they stay in a class where the teaching is collective and not adequately individually oriented, as is the case in the traditional school. Deviations from this pattern can be found, but they do not dominate.' (Emanuelsson et al., 2005, p. 119; cf. Bartolo, 2001; King et al., 2000; Spiteri et al., 2005)

\section{Widening the inclusion agenda}

A second important development in inclusive education in Malta has been the recent widening of the application of the inclusion philosophy beyond disability to the rights of all persons, particularly regarding immigrant minorities, to participate actively in society (see UNESCO, 2005). Disability and minority cultures have generally been addressed as separate issues in education: For instance, the recent review of research on teacher education in the USA split diversity issues into two chapters: one reviewed research on 'preparing teachers for diverse populations' and another on 'preparing general education teachers to work with students with disabilities' (Cochran-Smith and Zeichner, 2005). In Malta, disability was the first minority challenge that raised issues of inclusion. Thus, in 1993, a national conference launching the first National Policy document on Special Education in Malta was completely focused on children with disability (Bartolo, 1994). A programme for inclusive education set up at the university in 1998 was also completely focused on disability issues. A few years later, however, a national curriculum focus group for inclusive education opened its Guidelines for the Implementation of the National Curriculum Policy on Inclusive Education with the subtitle: 'Inclusion Is for All Students' (Bartolo et al., 2002, p. 1) that was also captured in the Maltese media. This development was spurred by Malta's drive for EU membership, where the multicultural perspective is more prominent than in Malta, and by concern about the rise of xenophobia as a result of the rise in illegal immigration from North Africa (Camilleri and Camilleri, 2008).

These developments were reflected in the faculty of education with three major activities: the co-ordination by the faculty of an EU Comenius 2.1 project in 2004-2007 on preparing teachers for 'student diversity' (http://www. dtmp.org), the launching of a Master of Education (MEd) in 'Responding to Student Diversity' (2005) and the setting up of a 'Programme for Culturally Responsive Education' in 2006 (Bartolo, Galea and Azzopardi, 2008). The faculty is also 1 of the 15 research partners in the EU FP6 project, 'INCLUD-ED - strategies for inclusion and social cohesion in Europe from education', co-ordinated by the University of Barcelona, Spain (http://www.ub.es/includ-ed).

Leaders of the disabled community, however, continue to feel that disability should not be 'diluted' by one wide category of diversity. Thus, although the KNPD has recently joined together the issue of racial discrimination and disability issues in the EU-funded campaign 'For Diversity - Against Discrimination' (http:// www.KNPD.org), it is, at the same time, seeking to set up at the university a centre for 'disability studies'.

\section{Socio-political dimension of inclusion}

In order to address teacher education issues, two particular developments in inclusive education in Malta that reflect the impact of the contextual factors in support of persons with disability and against immigrants must be considered. In Malta, sensitisation to the rights of persons with disability did not automatically transfer to other groups - a clear example of the contextualised sensitisation on inclusion and discrimination within particular social groupings (Artiles and Dyson, 2005). Although Maltese society has now become used to having people with disability in mainstream schools, at work, on national media programmes and in community activities, it was shown to be very intolerant vis-à-vis racial issues related to illegal immigration. Thus, in one particular school where all children are now infused with the ethos of acceptance and support for children with disability, the head noticed that two black children - who are actually Maltese born and have full Maltese citizenship - were irritated by being frequently asked by new peers whether they were 'refugees'. Recently, during a visit to a village primary school, it was observed that a student who was black, though actually adopted rather than an illegal immigrant, had to be seated apart from his peers on the insistence of the other children's parents, though he was observed interacting very naturally with his classmates during shared tasks.

These contrasts appear to be related to the national sociopolitical context. On one hand, the Maltese Catholic society has responded positively to the political emphasis on social welfare and empathy for persons with disability. Persons with disability have now been empowered to speak for themselves and emphasise the rights-based approach. On the other hand, the general population has reacted with xenophobia to the sudden arrival of illegal immigrants, many of whom are black and Muslim. Although children with disabilities are often provided with one-on-one additional support, other vulnerable children (including about 700 Muslim students) have no provision for their religious education and are thus excluded from religion lessons, 
having to stay in a corner or to go to the school library or elsewhere during the regular religion lessons at school.

\section{Impact of strategic promotion of inclusive education}

Another interesting political dimension is the choice of strategy for promoting inclusive education. The fast development of integration over the past two decades was partly the result of a strategic decision by leaders in the inclusion movement. Traditional educators insisted on a slow introduction of integration of children with disability to allow the schools to prepare themselves gradually for their intake. But the promoters of the inclusion initiative pushed through the other strategy of fast change, suggesting that all children be placed in regular school and, thus, forcing change on the system, as reported for Norway (Emanuelsson et al., 2005). Forcing this strategy is seen as having had positive and negative consequences. It is now partly blamed for the achievement of integration without inclusion. The teachers' union, which was not in agreement with the fast development, only accepted the fast integration on condition that children with disabilities have an assistant who would be responsible for the child with disability, though class size was reduced to not more than 26. Four important consequences have been identified:

1. The level of integration of children with IENs in regular schools made it easier for the development of a NMC (MOED, 1999) document that established the ideal of a quality education for all and did not distinguish between regular and special education.

2. The first option for all children in Malta is now truly mainstream schooling, with only very few children with rare conditions not attending primary schools. Interestingly, although statementing boards in other countries may have placement issues as their main decision goal, in Malta, the board's main consideration is the level of LSA to assign to the child with IEN: whether full time, one-on-one support or some form of shared support. Maltese observers in London and Hong Kong schools have noted a contrasting implicit assumption of educational administrators there as these distinguished between children with mild to moderate levels of impairment who were seen as potential candidates for integration, and those with severe learning difficulties and disabilities who were considered as 'natural' candidates for special schooling. In Malta, there are many who question what a particular child might be getting from integration in the mainstream, but the question is not raised categorically as there is an implicit assumption that all children should be placed in regular education at least at primary level.

3. Paradoxically, the strategy for fast inclusion for all in Malta did not take regular teachers on board and often meant that teachers did not take responsibility for the child with IEN. This was evidenced most conspicuously in the practice that if the LSA did not turn up, the child was sent back home: This is now corrected through having 'on-call' LSAs as replacement, but the practice is not yet fully effective
(Spiteri et al., 2005). We are still struggling with this development as teachers and parents, and schools simply emphasise the disabilities of their students in order to get ever more LSA support to the extent that, in a few instances, there are three of them in the same class.

4. Another impact of fast integration was the initial employment of untrained assistants and the subsequent focus on their training rather than on the training of regular teachers in inclusive education (Spiteri et al., 2005).

\section{Teacher education initiatives for inclusion}

The political developments for inclusion mentioned above that occurred in the late 1980s and early 1990s, together with the frames of mind of faculty deans and heads of the department, had an impact also on the university and on teacher education.

The Faculty of Education at the University of Malta - the only teacher education institution so far on the islands - was set up in 1978. It was a development from post-war teacher education colleges. It has four teacher education departments - primary education, secondary science education, secondary arts-and-languages education and education studies (philosophy, psychology and sociology of education) - with two other departments from related disciplines, namely, youth and community studies, and psychology. It currently serves around 1400 students in 4-year Bachelor of Education (BEd) degrees, 1-year postgraduate certificate in education (PGCE) and 3-year evening MEd and MA courses for qualified teachers.

\section{Special education issues as part of regular teacher education}

Unlike many other countries, Malta did not develop programmes of initial teacher training for special education. Since the 1950s, special education teachers had been trained mostly in the UK. (It could also be argued that Malta did not develop specialised forms of educational provision as special schools were more child minding than educational facilities.) Thus, there has been no conflict at the level of teacher education between old training programmes for special education and newer ones for support for inclusive education as has been reported in other countries (e.g., Avissar, 2007). There was, at one time, some pressure from a US framework for setting up a BEd in special education, but this was successfully resisted at the faculty on the basis of it being an exclusive process as it segregates special teacher education from regular teacher education even at the training level.

From within educational psychology, however, since the set up of the faculty in 1978, two units related to support for learning had been offered within the regular BEd teacher education programme: one was on 'handicaps in learning' (later called 'barriers to learning' and is no longer compulsory) and the other on 'mixed ability teaching' (now 
'responding to student diversity'). Meanwhile, credits on gender equality started being offered from sociology of education.

\section{Impact of political commitment to inclusion}

The new political initiative for inclusion in the late 1980s led to new initiatives by the university. Two projects with national impact started in 1989: First, a relatively wellfunded project for the multidisciplinary assessment of all children in special education was undertaken by the department of sociology in collaboration with the departments of health and education, and second, the faculty of education launched the first post-qualification evening diploma for teachers in education for 'children with special learning needs' that has since continued under different forms.

The faculty was also influenced by its engagement in the activities of the KNPD to influence policy. In 1992, a new NGO (then called Eden - now the Inspire Foundation for Inclusive Education) led by an ex-politician and father of a child with Down's syndrome advocated for the development of multidisciplinary services for children with disabilities. The leaders of Inspire's multidisciplinary services were two members of the department of psychology at the faculty of education, who were also connected to the KNPD. This NGO initially declared that all children should be given an opportunity to be educated in regular school and have an opportunity to develop independence and get a job, and all special schools should be closed. The rector of the university too was engaged in furthering the work of this NGO and was therefore instrumental in the setting up of the programme for inclusive education in the faculty of education. This programme, with government support and in collaboration with the EDEN Foundation, started its first diploma course for the training of LSAs (at the time called 'facilitators') to enable the inclusion of children with IEN and has since continued to offer such programmes. In 1993, the KNDP started offering a unit on 'disability issues' focused on the social model of disability and offered to different courses, including the BEd courses. The focus on the social model led to a review also of the sequence in which units related to disability should be offered: It was decided that the unit on disability issues (later combined with one on inclusive education) should precede units that focused on impairments within the individual.

\section{Impact of leadership committed to inclusion}

Meanwhile, the faculty was also closely involved in the development of a more inclusive national policy that gradually adopted issues of IEN as an essential part of mainstream education. The faculty deans were closely engaged in two ministerial consultations that produced documents that have led the debate on inclusive education: The first on Tomorrow's schools (Wain et al., 1995), which also included a representation from the KNPD, clearly declared 'the responsibility of the school to acknowledge, understand and respond to the different learning needs of individuals and groups, and to cater for them effectively in order to provide what is the entitlement of all: a quality education.' The second more important document was the drafting of a NMC, consisting mostly of principles and which was adopted unanimously by the Maltese Parliament in 1999. The idea of 'a quality education for all' permeated the whole document. Four of its 15 principles concerned inclusive education directly: Principle 1 - A quality education for all; Principle 2 - Respect for diversity; Principle 8 - Inclusive education; and Principle 9 - A more formative assessment. In order to facilitate movement towards implementation of the principles of the NMC (MOED, 1999), the National Curriculum Council set up 14 'focus groups', each made up of six experts in the relevant areas, most of which were led by faculty staff. The focus group 'for inclusive education' widened the inclusion agenda from disability to all minorities, also making use of an adapted version of the Index for Inclusion (Bartolo et al., 2002; Booth and Ainscow, 2002) in in-service work with schools. Thus, although some lecturers continued to uphold the strict streaming and exclusive system, the dominant faculty approach had become pro-inclusion, and this was formally adopted as a faculty principle in 1998.

This process was reflected in a gradual increase in input on inclusive education issues in the BEd programme. New areas related to inclusion were introduced in the primary area. One of these was input on 'interpersonal skills': This was soon taken up by the whole faculty as an important issue in teacher education and has become an inherent part (four European Credit Transfer System [ECTS]) of the BEd curriculum. Other important additions were units on 'individual educational planning' and 'differentiated teaching'. Similarly, a unit on 'inclusive education' was introduced into the PGCE, where, additionally, 'responding to diversity' became one of four themes raised within the educational psychology input.

In 2004-2007, the faculty co-ordinated an EU-funded Comenius 2.1 project, titled 'Differentiated Teaching Module - Primary (DTMp): Preparing Trainee Teachers for Responding to Pupil Diversity', among higher education institutions from seven European countries - Czech Republic, Germany, the Netherlands, Lithuania, Malta, Sweden and UK. The project produced a teacher's handbook in seven languages and a tutor's manual and reader for responding to student diversity in teacher education (Bartolo, Ale and Calleja et al., 2007a; Bartolo, Ale and Calleja et al., 2007b; Bartolo, Hofsaess and Mol Lous, 2007c), as well as an international study on primary school teachers' response to diversity in the classroom (Humphrey, Bartolo and Ale et al., 2006). The training materials were also used for online delivery in three of the countries (Bartolo, 2010).

The importance of leadership. The formal adoption of inclusive education as a faculty principle took place under a dean from sociology who valued the importance of addressing the needs of marginalised groups. It was found to be easier to increase input on inclusion in the primary education area with a head of department who was sensitive to a social justice agenda than in the secondary area where heads of the department had more listening ears for the subject specialists' calls for more subject-based pedagogical input - which 
may also be related to the nature of differences between primary and secondary curricula and organisation (Campbell-Whatley, Obiakor and Algozzine, 1995; Emanuelsson et al., 2005; Sattler and Graham, 1983). Secondary area heads also generally tended to emphasise what they called 'pragmatic' issues, arguing that it was much more important for students to have input on how to deal with challenging behaviour than the more attitudinal and 'philosophical' approaches of the unit on disability issues and inclusive education. However, in situations where heads of department were sensitive to IEN, more input could be negotiated, although it might be removed by the next head that lacked the same sensitivity. In the secondary area, most impact was achieved when one subject specialist took on the inclusion agenda herself within her pedagogical input and even sought, at times, relevant input from inclusion specialists.

In addition to input in initial teacher education, the faculty also developed four areas for master's programmes to support inclusive education. One was a MEd in responding to student diversity that arose out of the Comenius project referred to above. The other was a MEd in inclusive education and IEN for the training of inclusion co-ordinators for primary and for secondary schools. This was complemented by a master's in inclusive education and community - open also to other service professionals besides teachers and highlighting another strand in the inclusion agenda, namely, the creation of inclusive communities. Finally, as issues of management of children with socio-emotional and behavioural difficulties (SEBD) became prominent in the schools, government also funded a MEd programme in the education of children with SEBD. Within this area, moreover, a university research centre was set up for the promotion of educational resilience and socio-emotional competence in schools (http://www.um.edu.mt/edres), which has initiated a European Network on SocioEmotional Competence.

\section{Continuing challenges}

Four major challenges have continued to be of concern in the education of teachers for diversity and inclusive education in Malta that have also been identified in other countries. These are strategic concerns and pedagogical concerns.

\section{Strategic concerns}

1. The faculty did not experience conflict between special versus regular teacher education (e.g., Avissar, 2007). But we still have to balance specialised training with maintenance of mainstream staff responsibility for all. Despite the findings that good education for children with IEN is good education for all (Florian, 2009), practitioners continue to raise issues of the need for expertise in addressing particular IENs and for specialist support. This was indeed experienced also in the provision of services by the Maltese NGO for persons with disabilities (EDEN): It first started with two equivalent multidisciplinary teams offering one service to all children with various forms of mental disability but soon found the need for its personnel and services to develop specialised skills and programmes such as one for children with autism (Borg and Bartolo, 2000). Similarly, in the first diplomas in SEN, an attempt was made at one time to have a first year of core training in inclusion to be followed by a second year with specialisation in SEBD and learning difficulties. A one-time specific diploma course for teachers of children with hearing impairment was also offered.

Currently, separate MEd training programmes are on offer: one for inclusion co-ordination in primary/secondary schools and one for education of children with SEBD, and another is planned for the education of children with specific learning difficulties. In each of these courses, specialised personnel are being given the message that they need to be facilitators and not owners of inclusion. In addition, attempts are being made for all teachers to be sensitised and committed to the new perspective for enabling the participation of all students. Opportunities are also sought for sensitising school administrations and regular teachers to policies and practices in inclusive education. This balance, however, is precarious as general service personnel tend to push different needs away into the hands of the experts, and specialist personnel do indeed tend to easily adopt the expert role. Maintaining shared responsibility and action is best achieved when teacher educators collaborate with staff in schools (e.g., Winn and Blanton, 2005).

2. Related to the above, there is the dilemma of how to balance offering specific units on inclusive education with the development of an inclusive pedagogy across subject specialties (sometimes termed 'infusion' - e.g., Voltz, 2003). The general feeling in the faculty has been that specific units on inclusive education are necessary and that these, together with master's level courses for the training of support personnel, should lead to the build-up of research and skills in the area of responding to diversity. However, it is also understood that the most impact is achieved through teaching practice where issues of inclusion are highlighted (Abt-Perkins, Hauschildt and Dale et al., 2000; Hutchinson and Martin, 1999; Jacobs, 2006). Because teaching practice supervision is mainly the responsibility of subject specialists, it becomes essential that these lecturers are themselves supportive of the inclusion agenda.

In order for this to be achieved, one has to make use of all opportunities for staff development in the area. One such opportunity was the launching of the NMC (MOED, 1999), and again, now, we are in the middle of an educational reform process that is addressing the removal of streaming and the provision of a quality education for all. Infusing inclusive education issues into the faculty institutional policy and practice remains an unending process (cf. Melnick and Zeichner, 1998). One long-term strategy that has not been formally addressed is the recruitment of lecturers who are already imbued with a commitment to inclusion. Although this appears to have been a natural development in the general pedagogy areas, particularly in philosophy and sociology of education, it has not been so evident in the subject specialist areas. 
Pedagogical issues

3. A key pedagogical issue concerns the balance between academic learning and contextualised experience. It is hard to educate student teachers in inclusive education when their experience at the faculty and during teaching practice in schools is in a context of an exclusive mentality.

In order to educate them in inclusion, we also need to educate them in inclusive settings both at university and in the schools. Our own faculty, for instance, does not yet have teacher educators with a disability or from other minority groups. When student teachers come back from teaching practice, they also report being confronted with an established exclusive system that respects only those students that fall within the norms for achievement and behaviour of the school. The faculty has not yet found it possible to be selective in the school placement for student teachers. The best option appears to be for faculty to engage in in-service work with teachers as well as other decision-makers in the education system for the development of inclusive schools.

4. Related to the above dichotomy between academic learning and teaching experience, there is the dilemma of how to balance inclusion theory with inclusive practice. Despite the wide acceptance of the politically correct rhetoric on inclusion, many of our teachers still refer to inclusive arrangements as 'utopia' -

particularly saying 'in the end it is what happens in the exam that counts'.

In the different fora on inclusive education I have attended, the promoters of inclusive education have invariably argued that it is a change in attitude to embrace diversity that is the most important dimension to address in the education of teachers for inclusive education. Among the six main teacher competencies that have been highlighted in the related field of culturally responsive education, the first three concern attitudes, namely, socio-cultural consciousness, affirming views of students from diverse backgrounds and self-responsibility for (and capability of) bringing about change to make schools more equitable (Villegas and Lucas, 2002). The seven partners in the Comenius DTMp project for the preparation of teachers for inclusive education had an explicit discussion on what to prioritise in the piloting of the training: Should it be skills training or attitude development? The option was clear:

\section{'To stimulate self development in the trainee towards a greater appreciation of the need for responding to student diversity, an attitude that the team regards as an essential element in enabling teachers to become truly responsive in the classroom.' (Bartolo et al., 2005, p. 36)}

Attitude change, however, is not achieved in 1 week or in one unit of learning. It is particularly difficult when one is dealing with candidates who, as reported elsewhere (e.g., Hollins and Guzman, 2005), appear to come from the more traditional sections of the population with little experience of diversity. I was recently faced by a very hard position taken by a cohort of BEd primary teachers who argued forcefully that it was very reasonable that Muslim students should be denied the possibility of having a Muslim education in Maltese schools as we are a Catholic country. We are still looking for better ways of developing teachers who are open to diversity and committed to inclusion for all.

However, it has also been my experience in both pre- and in-service teacher education that there is often a request for practical strategies on how to implement inclusive education in the classroom. Teacher educators need to respond to this request. Although the emphasis has to remain on reflective practice, teacher educators can share the challenge of creating inclusive environments, curricula, and teaching and learning situations that engage all learners actively (Bartolo et al., 2008). This is indeed the spirit of the second recommendation of the 48th UNESCO International Conference on Education, which calls for efforts to:

\section{'Train teachers by equipping them with the appropriate skills and materials to teach diverse student populations and meet the diverse learning needs of different categories of learners through methods such as professional development at the school level, pre-service training about inclusion, and instruction attentive to the development and strengths of the individual learner.' (UNESCO, 2008)}

One of the ways in which this challenge is being addressed is through a practical unit on responding to student diversity using the teacher's handbook (Bartolo et al., 2007a): Lectures present strategies for differentiated teaching, and students are then expected to implement them during their teaching practice in the schools through a project for the effective engagement of a student in their class whom they consider to be at risk of exclusion. Meanwhile, in-service training is offered to all schools by a faculty programme in collaboration with the education division on the use of a learning style inventory based on four 'learning patterns' (http://www.letmelearn.org). Both pre-service and in-service teachers, however, continue to call for practical models and support in inclusive teaching arrangements.

\section{Conclusion}

The Maltese experience towards inclusive education and teacher education for inclusion bear evidence to the dictum that inclusive education is a process, not a destination (Ainscow, 1999). It can perhaps be seen as a primary motivational ideal that educators need to constantly work towards. With the support of political and educational leaders, there has been significant progress in the mainstreaming of students with IENs in Malta, but there is a much longer way to go for the achievement of curricula, class organisation and teaching that is truly open and accessible to all. Similarly, inclusion has been put on the agenda for teacher education, but it must be acknowledged that there is still a feeling among student teachers, and also among a significant number of teacher educators, that inclusive education is fine as something to talk about but not a 
feasible option in schools. Promoters of inclusive education have to find ever more effective ways of persuading teacher educators and teachers that adopting a commitment towards a quality education for all is a social justice obligation and that it is also a beneficial guide to the way we organise and practice effective education for all.

Address for correspondence

Paul A. Bartolo,

Faculty of Education,

University of Malta,

Msida MSD 2080

Malta.

Email: paul.a.bartolo@um.edu.mt.

\section{References}

Abt-Perkins, D., Hauschildt, P. \& Dale, H. (2000)

'Becoming multicultural supervisors: lessons from a collaborative field study.' Journal of Curriculum and Supervision, 16 (1), pp. 28-47.

Ainscow, M. (1999) Understanding the Development of Inclusive Schools. London: Falmer.

Artiles, A. \& Dyson, A. (2005) 'Inclusive education in the globalisation age: the promise of comparative cultural-historical analysis.' In D. Mitchell (ed.), Contextualizing Inclusive Education, pp. 63-88. London: Routledge.

Avissar, G. (2007) 'Teacher education in an inclusive era: ideologies and current policies in the state of Israel.' In P. A. Bartolo, T. Hofsaess \& A. Mol Lous (eds), Responding to Student Diversity: Teacher Education and Classroom Practice, pp. 107-24). Msida, Malta: University of Malta.

Bartolo, P. A. (1994) 'What is your vision for Malta?' The Sunday Times, 20 February 1994, p. 39.

Bartolo, P. A. (2001) 'Recent developments in inclusive education in Malta.' Mediterranean Journal of Educational Studies, 6 (1), pp. 65-91.

Bartolo, P. A. (2003) 'Inclusive schools: a challenge for developing an inclusive European society.' Journal of Maltese Education Research, 1 (1), pp. 167-73.

Bartolo, P. A. (2010) 'Teacher education online: towards inclusive virtual learning communities.' In C. Forlin (ed.), Teacher Education for Inclusion: Changing Paradigms and Innovative Approaches, pp. 120-9. London: Routledge.

Bartolo, P. A., Agius Ferrante, C., Azzopardi, A., Bason, L., Grech, L. \& King, M. (2002) Creating Inclusive Schools: Guidelines for the Implementation of the National Minimum Curriculum Policy on Inclusive Education. Floriana, Malta: Ministry of Education.

Bartolo, P. A., Ale, P., Calleja, C., Hofsaess, T., Humphrey, N., Janikova, V., Mol Lous, A., Vilkiene, V. \& Wetso, G. (2007a) Responding to Student Diversity: Teacher's Handbook. Msida, Malta: University of Malta.
Bartolo, P. A., Ale, P., Calleja, C., Cefai, C., Chetcuti, D., Hofsaess, T., Humphrey, N., Janikova, V., Mol Lous, A., Vilkiene, V. \& Wetso, G. (2007b) Responding to Student Diversity: Tutor's Manual. Msida, Malta: University of Malta.

Bartolo, P. A., Hofsaess, T. \& Mol Lous, A. (eds) (2007c) Responding to Student Diversity: Teacher Education and Classroom Practice. Msida, Malta: University of Malta.

Bartolo, P. A. \& Borg, G. (2009) 'The development of inclusive education in Malta.' In G. Bunch \& A. Valeo (eds), Inclusive Education: Emergent solutions, pp. 224-62. Toronto, ON, Canada: Inclusion Press.

Bartolo, P. A., Galea, S. \& Azzopardi, A. (guest eds) (2008) 'Culturally responsive education.' Malta Review of Educational Research, 6 (1) (Introduction to the Special Issue on Culturally Responsive Education).

Bartolo, P. A., Ale, P., Calleja, C., Hofsaess, T., Humphrey, N., Janikova, V., Mol Lous, A., Vilkiene, V. \& Wetso, G. (2005) DTMp: A Comenius 2.1 Project to Produce a Differentiated Teaching Module for Primary School Trainee Teachers. Refereed proceedings of the ATEE Conference in Amsterdam, October 2005. <http://www.atee2005.nl/download/ papers/04_ac.pdf> (accessed October 30 2009).

Barton, L. \& Tomlinson, S. (1981) 'Introduction: a sociological perspective.' In L. Barton \& S. Tomlinson (eds), Special Education: Policy, Practices and Social Issues, pp. 13-29. London: Harper \& Row.

Bezzina, F. (ed.) (2007) Rights Not Charity: Guidelines towards an Inclusive Society and a Positive Difference in the Lives of Maltese and Gozitan Disabled People. Santa Venera, Malta: KNPD.

Booth, T. \& Ainscow, M. (2002) Index for Inclusion: Developing Learning and Participation in Schools. (Rev. edn). Bristol: CSIE.

Borg, M. G. \& Bartolo P. A. (eds) (2000) Autism: The Challenge of Inclusion. Zejtun, Malta: The Eden Foundation.

Brown, R. C. (2005) 'Inclusive education in Middle Eastern cultures: the challenge of tradition.' In D. Mitchell (ed.), Contextualizing Inclusive Education, pp. 253-78. London: Routledge.

Camilleri, J. \& Camilleri, K. (2008) 'Do I belong? Psychological perspectives and educational considerations of young immigrants' school experiences.' Malta Review of Educational Research, 6 (1), pp. 64-79.

Campbell-Whatley, G. D., Obiakor, F. \& Algozzine, B. (1995). 'Perceptions of competencies for including students with disabilities in elementary and secondary school classrooms.' Special Services in the Schools, 10 (1), pp. 79-93.

Cochran-Smith, M. \& Zeichner, K. M. (eds) (2005) Studying Teacher Education: The Report of the AERA Panel on Research and Teacher Education. Mahwah, NJ: Lawrence Erlbaum.

Daniels, H. \& Garner, P. (1999) 'Introduction.' In H. Daniels \& P. Garner (eds), World Yearbook of 
Education 1999: Inclusive Education, pp. 1-10.

London: Kogan Page.

Emanuelsson, I., Haug, P. \& Persson, B. (2005) 'Inclusive education in some western European countries: different policy rhetorics and school realities.' In D. Mitchell (ed.), Contextualizing Inclusive Education, pp. 114-38. London: Routledge.

Equal Opportunities (Persons with Disability) Act, CAP 413 (2000). <http://docs.justice.gov.mt/lom/legislation/ english/leg/vol_13/chapt413.pdf > (accessed October 20 2009).

Florian, L. (2009) 'Towards an inclusive pedagogy.' In P. Hick, R. Kershner \& P. Farrell (eds), Psychology for Inclusive Education, pp. 38-51. London: Routledge.

Hollins, E. R. \& Guzman, M. T. (2005) 'Research on preparing teachers for diverse populations.' In M. Cochran-Smith \& K. M. Zeichner (eds), Studying Teacher Education, pp. 477-548. Mahwah, NJ: Lawrence Erlbaum.

Humphrey, N., Bartolo, P., Ale, P., Calleja, C., Hofsaess, T., Janikova, V., Mol Lous, A., Vilkiene, V. \& Wetso, G. (2006) 'Understanding and responding to diversity in the primary classroom: an international study.' European Journal of Teacher Education, 29 (3), pp. 305-18.

Hutchinson, N. L. \& Martin, A. K. (1999) 'Fostering inclusive beliefs and practices during preservice teacher education through communities of practice.' Teacher Education and Special Education, 22, pp. 234-50.

Jacobs, J. (2006) 'Supervision for social justice: supporting critical reflection.' Teacher Education Quarterly, 33 (4), pp. 23-39.

King, M., Bartolo, P., Borg, G., Bugeja, T., Camilleri, J., Cascun, C., Grech, L., Mallia, F., Sammut, P., Scerri, D., Tanti Burlo, E. \& Torre, J. (2000) 'Inclusive education.' In J. Giordmaina (ed.), National Curriculum on Its Way: Proceedings of Conference on the Implementation of the National Curriculum, Malta, 9-11 June 2000, pp. 25-46. Floriana, Malta: MOED.

KNPD (2009) Pre-Budget Document 2009: KNPD Proposals. Santa Venera, Malta: KNPD. <https:// www.budget2010.com.mt/media/submissions/ KNPD.pdf $>$ (accessed January 14 2010).

Manchester City Council (2010) 'Disabled people: disabled people and terminology.' <http:// www.manchester.gov.uk/info/200041/ equality_and_diversity/106/disabled_people/4> (accessed April 5 2010).

Melnick, S. L. \& Zeichner, K. M. (1998) 'Teacher education's responsibility to address diversity issues: enhancing institutional capacity.' Theory into Practice, 37 (2), pp. 88-95.

Ministry of Education (MOED) (1999) National Minimum Curriculum: Creating the Future Together. Floriana, Malta: Ministry of Education.

Organisation for Economic Co-operation and Development (1999) Inclusive Education at Work: Students with Disabilities in Mainstream Schools.
Paris: Organisation for Economic Co-operation and Development.

Sattler, J. L. \& Graham, L. P. (1983) 'Special education content included in regular teacher education programs.' Teacher Education and Special Education, 6 (2), pp. 124-30.

Spiteri, L., Borg, G., Callus, A. M., Cauchi, J. \& Sciberras, M. (2005) Inclusion and Special Education Review. Floriana, Malta: Ministry of Education.

Stainback, W. \& Stainback, S. (eds) (1990) Support Networks for Inclusive Schooling: Interdependent Integrated Education. Baltimore, MD: P.H. Brookes.

United Nations (UN) (2008) 'Panel discussion: mainstreaming disability in the development agenda, 12.02.08.' <www.un.org/disabilities/ default.asp?id=358> (accessed April 5 2010).

United Nations Educational and Scientific Organization (UNESCO) (1994) The Salamanca Statement and Framework for Action on Special Needs Education, World Conference on Special Needs Education. Paris: UNESCO.

United Nations Educational and Scientific Organization (UNESCO) (2005) Guidelines for Inclusion: Ensuring Access to Education for All. Paris: Author.

United Nations Educational and Scientific Organization (UNESCO) (2008) Inclusive Education: The Way of the Future. Conclusions and Recommendations of the 48th Session of the International Conference on Education (ICE). Geneva: UNESCO.

Villegas, A. M. \& Lucas, T. (2002) 'Preparing culturally responsive teachers.' Journal of Teacher Education, 53 (1), pp. 20-32.

Voltz, L. (2003) 'Collaborative infusion: an emerging approach to teacher preparation for inclusive education.' Action in Teacher Education, 25 (1), pp. $5-13$.

Wain, K., Attard, P., Bezzina, C., Camilleri, R., Darmanin, M., Farrugia, C., Psaila, A., Sammut, J., Sultana, R. \& Zammit, L. (1995) Tomorrow's Schools: Developing Effective Learning Culture: Report of the Ministerial Consultative Committee on Education. Floriana, Malta: Ministry of Education.

Warnock, M. (1978) Special Educational Needs: Report of the Committee of Enquiry into the Education of Handicapped Children and Young People. London: Her Majesty's Stationery Office.

Williams, T., Lamb, B., Norwich, B. \& Peterson, L. (2009) 'Special educational needs has outlived its usefulness: a debate.' Journal of Research in Special Educational Needs, 9 (3), pp. 199-217.

Winn, J. \& Blanton, L. (2005) 'The call for collaboration in teacher education.' Focus on Exceptional Children, 38 (2), pp. 1-10.

Zammit Mangion, J. (1992) Education in Malta. Pieta, Malta: Studia Editions.

Zammit Marmara, D. (2001) 'The ideological struggle over comprehensive education in Malta.' In R. G. Sultana (ed.), Yesterday's Schools: Readings in Maltese Educational History, pp. 253-81. San Gwann, Malta: PEG. 